\title{
The Detection of Mercury Vapour
}

\section{A NEW USE FOR THIN GOLD FILMS}

\section{John J. MeNerney and Peter R. Buseck}

Departments of Chemistry and Geology, Arizona State University, Tempe, Arizona

A portable instrument has been developed based on the resistance changes in a thin gold film caused by the adsorption of elemental mercury vapour. The technique is simple and rapid, with a limit of detection of 0.05 nanogram of mercury. The instrument is currently being used both in geochemical prospecting and in pollution studies.

In recent years considerable attention has been focused on the development of instrumental methods for the detection of low concentrations of mercury vapour, both for environmental studies and for geochemical prospecting. A portable instrument capable of rapid inexpensive analysis is desirable for these purposes. A variety of instruments has been produced, based primarily on the principle of atomic absorption (1), but, although such instruments are quite sensitive, interfering substances such as $\mathrm{SO}_{2}, \mathrm{H}_{2} \mathrm{O}$ and a variety of organic compounds have proved a serious limitation. In overcoming these interferences the resulting instrumentation has become increasingly complex and expensive, with a corresponding decrease in both portability and ease of operation.

We have developed an extremely sensitive, lightweight field-portable mercury detector based on the phenomenon that a thin gold film (several hundred Ångströms in thickness) undergoes a significant increase in resistance upon the adsorption of mercury vapour $(2,3)$. The change in resistance

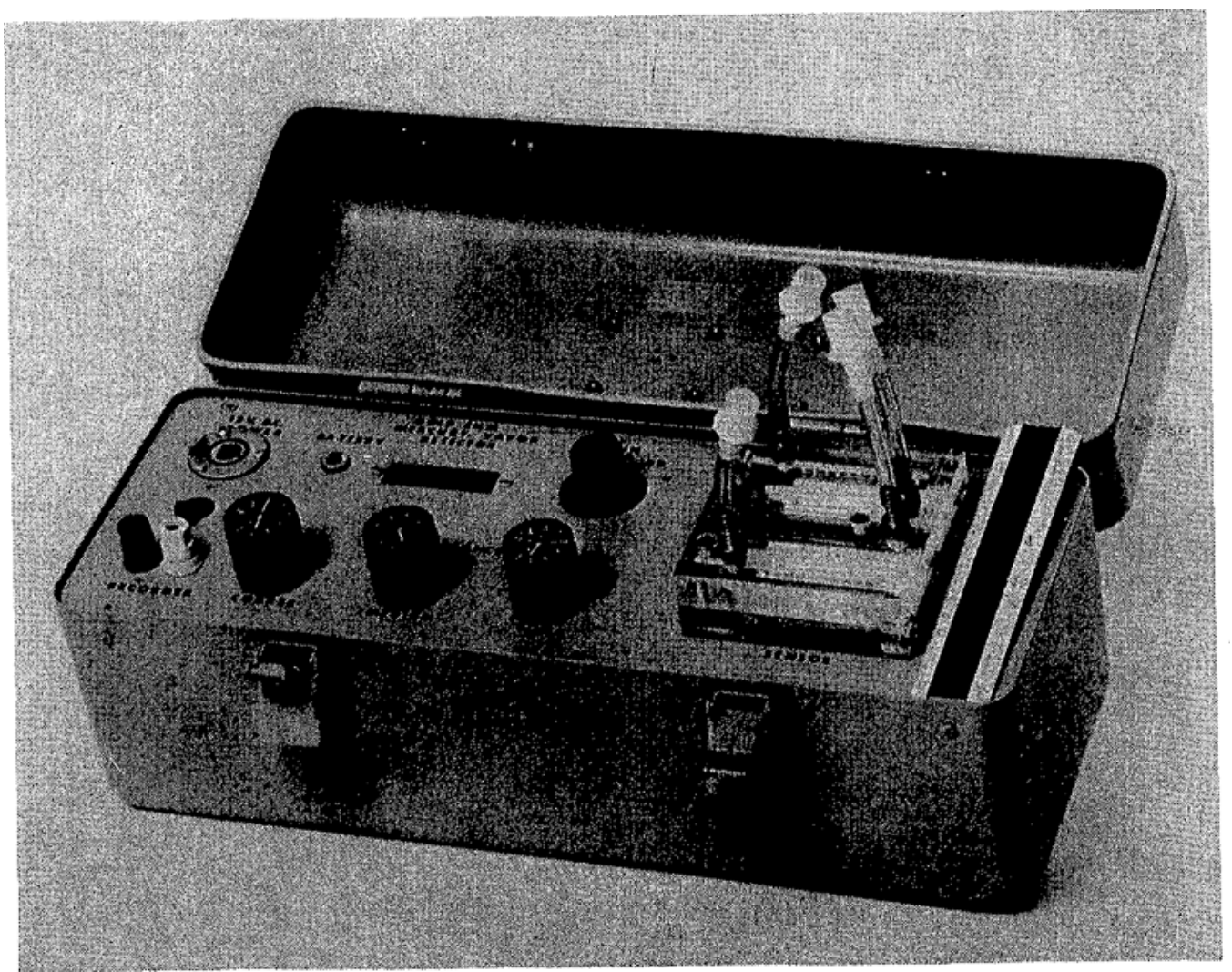

The prototype gold film mercury detector. The plexiglas chamber housing the gold films is visible on the right of the photograph 
of gold films is due to an increase in scattering of conduction electrons at the gold film surface upon adsorption of mercury atoms.

The gold films used as sensing elements in our detector are prepared by vacuum evaporation on ceramic or glass substrates in a conventional high vacuum system $\left(10^{-6}\right.$ Torr). Two films, one a sensor and the other a reference, are connected into opposite arms of a single d.c. bridge circuit and balanced. The reference film is used to compensate for resistance changes due to thermal fluctuations.

The success of the gold film mercury detector depends on several unique properties of gold:

(a) the well-known affinity of mercury for gold;

(b) the large electrical changes produced in a thin gold film when small amounts of mercury are adsorbed; and

(c) the relative chemical inertness of gold to other gases.

The instrument has been used extensively during the past two years in both geochemical prospecting and pollution studies. The development of this instrument was part of a research project into the measurement of minute quantities of mercury vapour present in soil gas over a variety of base and precious metal deposits, which often contain trace amounts of mercury. As these deposits oxidise the mercury is released, and, being highly volatile, is often able to migrate to the surface. Anomalous concentrations of this mercury vapour in soil gas are therefore often indicative of base or precious metal deposits at depth. This prospecting technique has considerable potential in the search for new ore deposits covered by alluvium or recent volcanics where conventional geochemical methods are normally unsuitable (4).

The gold film mercury detector is ideally suited for this method of prospecting as it can measure as little as $5 \times 10^{-11} \mathrm{~g}$ of mercury in the field. This compares well with a good laboratory atomic absorption facility which is capable of measuring $10^{-9} \mathrm{~g}$.

An additional application for this instrument has been in the field of mercury pollution, which has received wide publicity both in the popular press and in technical literature. A recently completed study involved the measurement of ambient mercury levels in the atmosphere in heavily industrialised areas. The portable nature of the instrument allowed on-site measurement, as well as specificity for mercury in air samples containing a wide spectrum of atmospheric pollutants.

The successful application of this instrument to a variety of geochemical and environmental problems where the measurement of minute quantities of mercury is important in establishing its use in the field of mercury analysis.

We would like to thank Selection Trust Limited of London for their generous support of this research project.

\section{References}

1 J. A. Goleb, Appl. Spectrosc. 1971, 25, 522; T. Hadeishi and R. D. McLaughlin, Science, 1971, 174, 404; W. R. Hatch and W. L. Ott, Anal. Chem., 1968, 40, 2085; C. Ling, ibid., p. 1876; W. W. Vaughn and J. H. McCarthy, Jr, U.S. Geol. Surv. Prof. Paper 501-D, 1964, p. D123

2 John J. McNerney, Peter R. Buseck and Roland C. Hanson, Science, 1972, 178, 611

3 U.S. Patent 3,714,562

4 John J. MCNerney and Peter R. Buseck, Economic Geology, 1973, in the press

\section{Diffusion and Precipitation of Gold in Lead}

The diffusion of gold into lead at room temperatures was the first example of diffusion between solid metals ever to be studied. In 1896 Sir William RobertsAusten clamped a cleaned disc of pure gold in contact with a lead cylinder and stowed the assembly away in the basement of the Royal Mint in London. Four years afterwards he separated the samples and sliced thin layers, the first 0.75 and the others $2.3 \mathrm{~mm}$ thick, from the surface of the lead. After fire assaying, he recovered $0.05 \mathrm{mg}$ of gold from the first layer, small gold beads visible under low power microscopy from the underlying two, and "spangles" from the fourth.

Quantitative data on the diffusion coefficients of gold in lead at room temperatures are still lacking, though it is known that the mechanism is much more complox than Roberts-Austen can have imagined. It appears that a small amount of gold goes into substitutional solid solution in lead, but that when gold is caused to diffuse through lead it does so only by an interstitial mechanism. The interesting consequence is that when gold atoms have finally to diffuse out of their positions in the lead lattice vacancies are left and the rate of further diffusion inevitably slows down.

Continuing a study of these atomic movements, A. N. Rossolimo and D. Turnbull, of Harvard University, have investigated the precipitation of particles of $\mathrm{Pb}_{3} \mathrm{Au}$ from quenched lead alloys containing 0.068 to 0.105 atomic per cent of gold after ageing at 27 to $215^{\circ} \mathrm{C}$ (Acta Metallurgica, 1973, 21, 21-34). The progress of precipitation was followed by observing changes of electrical resistivity. The particles were in the form of "small oblate ellipsoids of revolution" and their rate of growth was, of course, determined by the rate at which gold atoms diffused to the nuclei which first formed. The precipitates grew relatively rapidly; it was estimated that about 97 per cent of the excess gold was precipitated from samples oil-quenched from $215^{\circ} \mathrm{C}$ after ageing for 130 minutes at $100^{\circ} \mathrm{C}$, and that 50 per cent was precipitated from water-quenched samples in 31 hours at $24^{\circ} \mathrm{C}$. The results are considered to indicate that during ageing gold atoms diffuse in small clusters, and that the diffusion rate of gold in lead should decrease markedly as the gold concentration increases. 